\title{
Influence of parental attitudes in the development of children eating behaviour
}

\author{
Silvia Scaglioni*, Michela Salvioni and Cinzia Galimberti \\ Pediatric Clinic S. Paolo Hospital University of Milan, Milan, Italy
}

The present paper is a review of available data on effects of parental feeding attitudes and styles on child nutritional behaviour. Food preferences develop from genetically determined predispositions to like sweet and salty flavours and to dislike bitter and sour tastes. There is evidence for existence of some innate, automatic mechanism that regulate appetite. However, from birth genetic predispositions are modified by experience. There are mechanisms of taste development: mere exposure, medicine effect, flavour learning, flavour nutrient learning. Parents play a pivotal role in the development of their child's food preferences and energy intake, with research indicating that certain child feeding practices, such as exerting excessive control over what and how much children eat, may contribute to childhood overweight. Mothers are of particular interest on children's eating behaviour, as they have been shown to spend significantly more time than fathers in direct interactions with their children across several familial situations.

A recent paper describes two primary aspects of control: restriction, which involves restricting children's access to junk foods and restricting the total amount of food, and pressure, which involves pressuring children to eat healthy foods (usually fruits and vegetables) and pressuring to eat more in general.

The results showed significant correlations between parent and child for reported nutritional behaviour like food intake, eating motivations, and body dis- and satisfaction. Parents create environments for children that may foster the development of healthy eating behaviours and weight, or that may promote overweight and aspects of disordered eating. In conclusion positive parental role model may be a better method for improving a child's diet than attempts at dietary control.

Understanding children's eating attitudes and behaviour is important in terms of children's health. Evidence also indicates that dietary habits acquired in childhood persist through to adulthood ${ }^{(1)}$. In addition, research also indicates a role for childhood nutrition on adult health ${ }^{(2)}$.

Parents provide food environments for their children's early experiences with food and eating. Several studies have shown that a child's eating behaviour is strongly influenced by the family environment. The family eating environments include parents' own eating behaviours and child-feeding practices. Results of research on behavioural mediators of familial patterns indicate that parents' own eating behaviours and their parenting practices influence the development of children's eating behaviours.

Parents create environments for children that may foster the development of healthy eating behaviours and weight, or that may promote overweight and aspects of disordered eating. Characteristics of these environments include socio-demographic factors, parental activity, parental eating styles ${ }^{(3)}$ and parents' child-feeding styles. Parents shape the development of children's eating behaviours, not only by the foods they make accessible to children, but also by their own eating styles ${ }^{(4)}$, behaviour at mealtimes and child feeding practices $^{(7)}$. Parent's child-feeding practices are associated with children's eating behaviours, including specific eating styles, food selection and preferences ${ }^{(5)}$, and the regulation of energy intake ${ }^{(6)}$.

\section{Innate}

\section{Food preferences}

Children's food preferences strongly influence intake and it is therefore vital to understand how these preferences arise. Psychological research is beginning to reveal the complex interplay of innate, learned and environmental factors which shapes children's eating patterns. Food preferences develop from genetically determined predispositions to like sweet and salty flavours and to dislike bitter and sour tastes. There is evidence for the existence of some innate, automatic mechanism that regulate appetite. In 1-3 years infants energy intake regulation is effective if there is a wide offer of plain foods.

With plain foods, children choose their diet and have a regular growth, without instructions from adults. Beside the theory of self-regulation there is evidence that eating behaviour can be learnt and it is possible to modify energy intake by a repeated offer. Taste acquisition for specific foods is a consequence of learning.

Young children are also predisposed to be neophobic about food. Particularly towards the second year of life, coinciding with an important period of transition to an adult diet, there is a tendency to avoid novel foods (neophobia). Neophobia (literally 'fear of the new') manifests itself as a rejection of unfamiliar foods in favour of familiar ones. In a survey of almost 600 2-6-year-old children, neophobia was significantly negatively associated with fruit, vegetable and meat intake ${ }^{(8)}$ THOUGH 
NOT WITH consumption of dairy foods, starchy staples or cakes and biscuits ${ }^{(9)}$.

Food aversions can be learnt in one trial if consumption is followed by discomfort. However, from birth genetic predispositions are modified by experience. There are mechanisms of taste development and positively associated with:

Mere exposure: the more exposure we have to a stimulus, the more we will tend to like it; foods which have been eaten more often tend to be liked more; this is the way that specific preferences grow in different cultures. Several studies suggest that an exposure based approach has promise for improving the quality of children's diets. Particular strengths of the technique are its simplicity and relatively low demands of both parents and children.

Medicine effect: we like better a food that we eat when we are healthy instead of a food proposed when we are ill.

Flavour learning: between 2 foods of different taste, administered one added with sugar and one without, there is preference for the first food also when proposed without sugar.

Flavour nutrient learning: the more a food is energy-rich the more is appreciated, this is a primordial model. Man can recognize the most caloric foods indispensable to life $\mathrm{e}^{(10)}$.

\section{Family environment}

In the experience context, during the early years, parents play a particularly important role. There are many variables within the family setting that can affect children's eating behaviour and, ultimately, their weight outcome. Included among these are parents' eating behaviours, foods made available to children, and child feeding strategies utilized. Parents play a pivotal role in the development of their child's food preferences and energy intake, with research indicating that certain child feeding practices, such as exerting excessive control over what and how much children eat, may contribute to childhood overweight ${ }^{(22)}$ (Table 1).

The children behaviours (dietary intakes-eating style, weight, physical activity) are influenced from parent characteristics. The family environment influence:

1. the children intake by eating styles, diet composition, food preferences, child-feeding practices, availability of energydense foods in the home, restaurant eating $v$. meals prepared at home, family meals $v$. eating away from the table

Table 1. Family factors that influence bidirectionally parents and child

\begin{tabular}{ll}
\hline Parent characteristics & Child characteristics \\
\hline Parents' weight status & $\begin{array}{l}\text { Dietary intakes } \\
\text { Eating style } \\
\text { Perceived responsability for child feeding }\end{array}$ \\
$\begin{array}{l}\text { Weight } \\
\text { Parent's dietary intake }\end{array}$ \\
$\begin{array}{l}\text { Food preferences } \\
\text { Feeding practice }\end{array}$ \\
$\begin{array}{l}\text { Portion size } \\
\text { Food available at home }\end{array}$ \\
$\begin{array}{l}\text { Food accessibility } \\
\text { Eating locations ambient temperatures and } \\
\quad \text { lighting }\end{array}$ \\
Time of consumption, ambient sounds \\
Temperature and smell of foods \\
Family meals $v$. eating away from table \\
Family income \\
Physical activity
\end{tabular}

From Davison \& Bearch 2001 Obesity Reviews.
2. the children energy expenditure by physical activity patterns, physical activity preference, metabolic rate, enjoyment of physical activity, encouraging children to be active, providing opportunities to be active

The parents can influence the development of children eating behaviour through a set of regulatory acts aimed at helping children adapt to their environments:

- Sustenance: providing food, protection from environment threats

- Stimulation

- Support

- Structure: organizing eating environments

- Surveillance: monitoring and control over eating

\section{Parental control}

A recent paper ${ }^{(5)}$ describes two primary aspects of control: restriction, which involves restricting children's access to junk foods and restricting the total amount of food, and pressure, which involves pressuring children to eat healthy foods (usually fruits and vegetables) and pressuring to eat more in general. Parents may use a combination of these methods to obtain a desired result; for example, pressuring a child to eat healthy foods by using bribes or rewards consisting of sugary snacks that are otherwise restricted ${ }^{(19)}$.

Parent restriction has short term and long term effect on children's intake. It enhances preference, increases attention and intake at first, then this curb increases intake, increases eating in the absence of hunger, doesn't produce ability to self-regulate diet but causes negative self evaluation, greater weight gain from 5 to 11 years $^{(5)}$.

Pressuring children to eat, likewise appears to be counterproductive, reducing children's ability to regulate their energy intake ${ }^{(6)}$. A further study ${ }^{(11)}$ has linked 'pressure to eat' to reduced consumption of fruit and vegetables in 5- year-old girls. A common assumption runs through these studies: that controlling children's intake of food is a causal factor in their poor eating patterns. It is entirely plausible, however, that the direction of causality runs counter to this; that, in fact, parents use of control is a response to unhealthy eating habits. Others researches have explored the impact of controlling food intake by rewarding the consumption of 'healthy food' as in 'if you eat your vegetables I will be pleased with you'. For example, Birch et al. ${ }^{(12)}$ gave children food in association with positive adult attention compared with more neutral situations.

This was shown to increase food preference; but as concluded by Birch: "although these practices can induce children to eat more vegetables in the short run, evidence from our research suggests that in the long run parental control attempts may have negative effects on the quality of children's diets by reducing their preferences for those foods."(13)

Initial evidence indicates that imposition of stringent parental controls can enhance preferences for high-fat and energy-dense foods, limit children's acceptance of a variety of foods and disrupt children's regulation of energy intake by altering children's responsiveness to internal cues of hunger and satiety. This can occur when well-intended but concerned parents assume that children need help in 
determining what, when, and how much to eat and when parents impose child-feeding practices that provide children with few opportunities for self-control ${ }^{(14)}$.

\section{Maternal influences}

Mothers are of particular interest on children's eating behaviour, as they have been shown to spend significantly more time than fathers in direct interactions with their children across several familial situations, including mealtimes ${ }^{(15)}$.

Mothers who exert a greater degree of control over their child's food intake had children who demonstrated less ability to regulate energy intake. External parental control of the child's dietary intake may indirectly foster the development of excess adiposity in the child.

Birch and colleagues ${ }^{(16,17)}$ point out that mothers, who were preoccupied with their own weight and eating, reported higher levels of restricting daughters' intake, encouraging daughters to lose weight over time. In this study, mothers' encouragement of daughters' weight loss was linked to daughters' restrained eating behaviour. This relationship was partially mediated by daughters' perception of maternal pressure to lose weight. These findings suggest that mothers' preoccupation with weight and eating, via attempts to influence daughters' weight and eating, may place daughters at risk for developing problematic eating behaviours.

The predictors of maternal child-feeding style are maternal and child characteristics. Birch and colleagues ${ }^{(5)}$ affirm that mothers reported using more restrictive feeding practices when they perceived daughters as overweight and reported using more pressure in child feeding when they perceived daughters as underweight.

Mothers' child-feeding practices were related to mothers' own investment in weight and eating related issues, daughters' observable weight status, mothers' perceptions of daughters' weight status, and mothers' concern for their daughter developing a weight problem in the future. This model held for maternal restriction, in that mothers reported greater use of restriction in child feeding when they had greater weight and eating concerns of their own, when daughters were overweight, when they perceived that their daughters were at risk for developing a weight problem, and when they had concerns about daughters' weight ${ }^{(18)}$.

\section{Recommendations for practice on nutritional behaviour}

The parental attitudes and behaviour are central to the development of children's eating habits, so it's important to give to the parents some strategies about their child's nutritional behaviour as:

1. Guidance for parents should include information on how children develop patterns of food intake in the family context.

2. Practical advice for parents includes how to foster children's preferences for healthy foods and how to promote acceptance of new foods by children.

3. Parents need to understand the costs of coercive feeding practices and be given alternatives to restricting food and pressuring children to eat

4. Setting a good example: parental role modelling is important in establishing children's food choice. Depending on their own foods choice, parents can be either positive or negative role models. For example in some study fruit and vegetable consumption is higher in children ${ }^{(20)}$ and adolescents ${ }^{(21)}$ who eat at the same time as their parents and in pre-schoolers who eat the same food at mealtimes which further supports this view. It's very important that parents, guardians and caregivers must provide appropriate role modelling through their own behaviour, that is, influence children to "do as I do" rather than "do as I say".

5. Respond to satiety clues and do not overfeed; infants and young children can usually self-regulate total energy caloric intake; do not force children to finish meals if not hungry

6. Parents should remember that they are responsible for choosing foods and when and where food should be eaten.

7. Two natural parental impulses, pressuring children to eat and restricting access to specific foods, are not recommended because they often lead to overeating, dislikes and paradoxical interest in forbidden items

8. Strategies to improving nutrition in young children are for parents, not children:

- to choose meal times;

- provide a wide variety of nutrient-dense foods, such as fruits and vegetables, instead of highenergy- density/nutrient-poor "junk" foods;

- age-appropriate portion size;

- limiting snacking and use of juice or sweetened beverages;

- allowing children with normal body mass index to self-regulate total caloric intake;

- having regular family meals to promote social interaction and role model food-related behaviour

- limit video and television watching to less than 2 hours daily.

\section{Conclusions}

The development of children's food preferences involves a complex interplay of innate, familial and environmental factors, not all of which are likely to promote a healthy and varied diet. Parents employ a variety of strategies to improve their children's eating habits some of which have been found to be counter-productive. Over-control, the offering of rewards, and the provision of nutrition information to children appear to have negative effects on food acceptance patterns. Parents own food preferences, on the other hand, are enormously influential and eating together as a family provides a valuable opportunity for parents to model good eating habits. Together with the evidence that repeated taste exposure can increase acceptance of healthy foods, these findings should inform the guidance given to parents during early childhood. Effective prevention programs must focus on providing anticipatory guidance on parenting to foster patterns of preference and food selection in children more consistent with healthy diets and promote children's ability to self-regulate intake. Guidance for parents should include information on how children develop patterns of food intake in the family context. Practical advice for parents 
includes how to foster children's preferences for healthy foods and how to promote acceptance of new foods by children. Parents need to understand the costs of coercive feeding practices and be given alternatives to restricting food and pressuring children to eat. Providing parents with easy-touse information regarding appropriate portion sizes for children is also essential as are suggestions on the timing and frequency of meals.

\section{Conflict of interest statement}

None of the authors has any conflicts of interest to report.

\section{References}

1. Kelder SH, Perry CL, Klepp K-I \& Lytle LL (1994) Longitudinal tracking of adolescent smoking, physical activity and food choice behaviours. Am J Public Health 84, 1121-1126.

2. Berenson GS, Srinivasan SR, Bao W, Newman WP III, Tracy RE \& Wattigney WA (1998) Association between multiple cardiovascular risk factors and atherosclerosis in children and young adults. $N$ Engl J Med 338, 1650-1656.

3. Fisher JO \& Birch LL (1999) Restricting access to foods and children's eating. Appetite 32, 405-419.

4. Cutting TM, Fisher JO, Grimm Thomas K \& Birch LL (1999) Like mother, like daughter: familial patterns of overweight are mediated by mothers dietary disinhibition. Am J Clin Nutr 69 , 608-613.

5. Birch LL, Fisher JO, Markey CN, Grimm Thomas K, Sawyer R \& Jonhnson SL (2001) Confirmatory factor analysis of the Child Feeding Questionnaire: a measure of parental attitudes, beliefs and practices about child feeding and obesity proneness. Appetite 36, 201-210.

6. Johnson SL \& Birch LL (1994) Parents' and children's adiposity and eating style. Pediatrics 94, 635-661.

7. Birch LL \& Fisher JO (2000) Mothers' child-feeding practices influence daughters' eating and weight. Am J Clin Nutr 71, $1054-1061$

8. Cooke L (2004) The development and modification of children's eating habits. Br Nutr Found Nutr Bull 29, 31-35.
9. Cooke L, Wardle J \& Gibson EL (2003) The relationship between child food neophobia and everyday food consumption. Appetite 41, 205-206.

10. Kissileff Harry R (1991) Chance and necessity in ingestive behavior. Appetite 17(1), 1-22.

11. Fisher JO \& Birch LL (2002) Eating in the absence of hunger and overweight in girls from 5 to $7 \mathrm{y}$ of age. Am J Clin Nutr 76, 226-231.

12. Birch LL (1980) Effects of peer models' food choices and eating behaviors on preschooolers' food preferences. Child Dev 51, 489-496.

13. Birch LL (1999) Development of food preferences. Апnи Rev Nutr 19, 41-62.

14. Brown R \& Ogden J (2004) Children's eating attitudes and behaviour: a study of the modelling and control theories of parental influence. Health Educ Res 19(3), 261-271.

15. Mc Hale SM, Crouter AC, McGuire SA \& Updegraff KA (1995) Congruence between mothers' and fathers' family relations and children's well being. Child Dev 66, 116-128.

16. Francis Lori A, Hofer Scott M \& Birch Leann L (2001) Predictors of maternal child-feeding style: maternal and child characteristics. Appetite 37, 231-243.

17. Shunk JA \& Birch LL (2004) Girls at risk for overweight at age 5 are at risk for dietary restraint, disinhibited overeating, weight concerns, and greater weight gain from 5 to 9 years. $J$ Am Diet Assoc 104(10), 1546-1547.

18. Johannsen Darcy L, Johannsen Neil M \& Specker Bonny L (2006) Influence of parents' eating behaviors and child feeding practices on children's weight status Obesity 14(3).

19. Sherry B, McDivitt J, Birch LL, et al. (2004) Attitudes, practices, and concerns about child feeding and child weight status among socioeconomically diverse white, Hispanic, and African-American mothers. J Am Diet Assoc 104, 215-221.

20. Gillman MW, Rifas-Shiman SL, Frazier AL, et al. (2000) Family dinner and diet quality among older children and adolescents. Arch Fam Med 9, 235-240.

21. Roos EB, Hirvonen T, Mikkila V, et al. (2001) Household educational level as a determinant of consumption of raw vegetables among male and female adolescents. Prev Med 33, 282-291.

22. Faith Myles S, Scanlon Kelley S, Birch Leann L, Francis Lori A \& Sherry Bettylou (2004) Parent-child feeding strategies and their relationships to child eating and weight status Obes Res 12(11), 1711-1722. 